\title{
OS ESPAÇOS VERDES NA HISTÓRIA DO RECIFE
}

\section{Ana Rita Sá Carneiro}

Professora Doutora da graduação e pós-graduação do Departamento de Arquitetura e Urbanismo da UFPE; coordenadora do Laboratório da Paisagem e membro do CECl - UFPE.

e-mail: anaritacarneiro@hotmail.com

\section{Colaboração}

\section{Aline de Figueirôa Silva}

Bolsista de iniciação científica do PIBIC-CNPq, acadêmica do curso de Arquitetura e Urbanismo da Universidade Federal de Pernambuco.

\section{Pricylla Amorim Girão}

Bolsista de iniciação científica do PIBIC-CNPq, acadêmica do curso de Arquitetura e Urbanismo da Universidade Federal de Pernambuco.

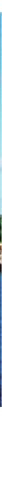




\section{RESUMO}

O objetivo deste texto é iniciar o debate sobre a avaliação da cobertura vegetal na cidade do Recife para a caracterização da paisagem de suas regiões, a partir dos dados da pesquisa Espaços Livres do Recife (2000). A avaliação tomou como base as linhas de força da paisagem que se evidenciam como elementos estruturadores: o rio Capibaribe, a mancha das unidades de conservação e a faixa do litoral, cada uma marcada por um elemento vegetal característico, a saber, mangues, espécies da mata atlântica e coqueiros, respectivamente. Os outros espaços livres como parques, praças e jardins, representados, predominantemente, pelos sombreiros, acácias e castanholas, encontram-se espalhados na malha urbana e não parecem estar articulados entre si nem com os elementos estruturadores. Dois aspectos nortearam essa avaliação: a leitura dos maciços vegetais nas linhas de força da paisagem e a perspectiva de resgate dos princípios estéticos e ecológicos que caracterizavam as antigas intervenções paisagísticas, priorizando uma articulação dos espaços verdes. Constata-se que, ao longo do tempo, a paisagem não foi conservada, passando-se da escala macro para a micro, atuando-se de forma pontual, o que fez configurar espaços livres fragmentados em um território denso de construções. A perspectiva de resgatar os espaços verdes está depositada em uma possível articulação entre eles, a partir das linhas de força da paisagem. Nesse sentido, a avaliação da cobertura vegetal consubstancia uma metodologia que aborda a escala macro das linhas de força e regiões da cidade até a escala micro dos bairros e espaços livres, destacando as referências históricas naturais e culturais visando a uma articulação desses espaços.

Palavras-chave: Espaços livres, espaços verdes, paisagismo, história do paisagismo.

\section{ABSTRACT}

The aim of this work is to start the debate about the evaluation of the greenery in the city of Recife as part of the landscape character of the regions taking into account the Recife Open Spaces Research in 2000. This evaluation is based on the landscape structure lines: the Capibaribe river, the protected green areas and the coast. Each of them is marked by a specific vegetation such as the mangrove, the atlantic forest species and the coconut trees. The other types of open spaces such as parks, squares, gardens are distributed in the urban space without any articulation between them and the landscape structure lines. Two aspects have conducted this first evaluation: the identification of the landscape structure lines and the rescue of the aesthetic and ecological principles from the oldest landscape designs which focusing the green spaces articulation. So, it shows that landscape has not maintained and conserved as it should, and the city passed to be planned in a "micro" scale creating isolated small open spaces without any articulation inside dense built space. The intention to rescue the green spaces is seeking an articulation between the small open spaces and the landscape structure lines. In this way, the evaluation of green spaces concerns a methodology which considers the "macro" scale focusing the landscape structure lines and the regions of the city, and the "micro" scale focusing the quarters and small open spaces, creating natural and cultural historical references and their articulation.

Key words: Urban open spaces, green areas, landscape architecture, landscape architecture history. 


\section{OS ESPAÇOS VERDES NA HISTÓRIA DO RECIFE}

\section{Introdução}

A pesquisa Espaços Livres do Recife identificou uma tipologia de espaços livres e formulou os conceitos desses espaços, introduzindo uma nova leitura do espaço urbano (SÁ CARNEIRO e MESQUITA, 2000). Constatou-se uma tipologia diversificada de espaços públicos - unidades de conservação, parques, praças, jardins, etc. - à qual se somou, de modo surpreendente, um conjunto considerável de espaços potenciais que garantiam não só o exercício de atividades de recreação, com os campos de pelada e os recantos de iniciativa da população, mas também o usufruto de áreas verdes privadas amenizadoras, denominadas espaços de valor paisagístico-ambiental, além das margens de rios e de canais. Tão representativos do contexto urbano, esses espaços quantificaram quase $50 \%$ dos 629 espaços livres encontrados na malha urbana. Se, por um lado, esse dado reflete uma carência de espaços públicos, principalmente daqueles encontrados e destinados à função de recreação - faixa de praia, parques, praças, pátios, largos, jardins e quadras polivalentes -, por outro lado, mostra a necessidade de incorporá-los ao conjunto dos espaços públicos, devido à importância que tais categorias exercem no cotidiano da população e, em especial, nos bairros pobres (Mapa 1).

Mapa 1: Mapa georreferenciado
dos espaços livres do Recife
Fonte: Sá Carneiro e Mesquita

(2000)

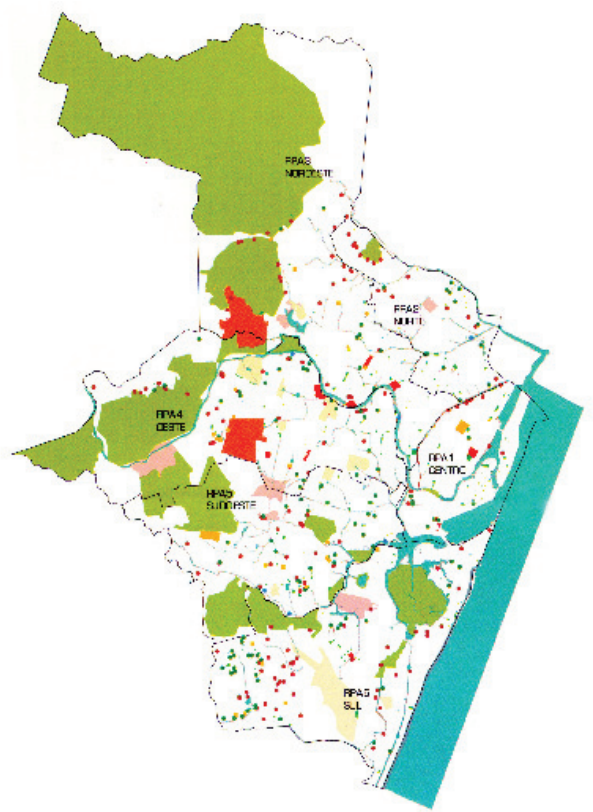




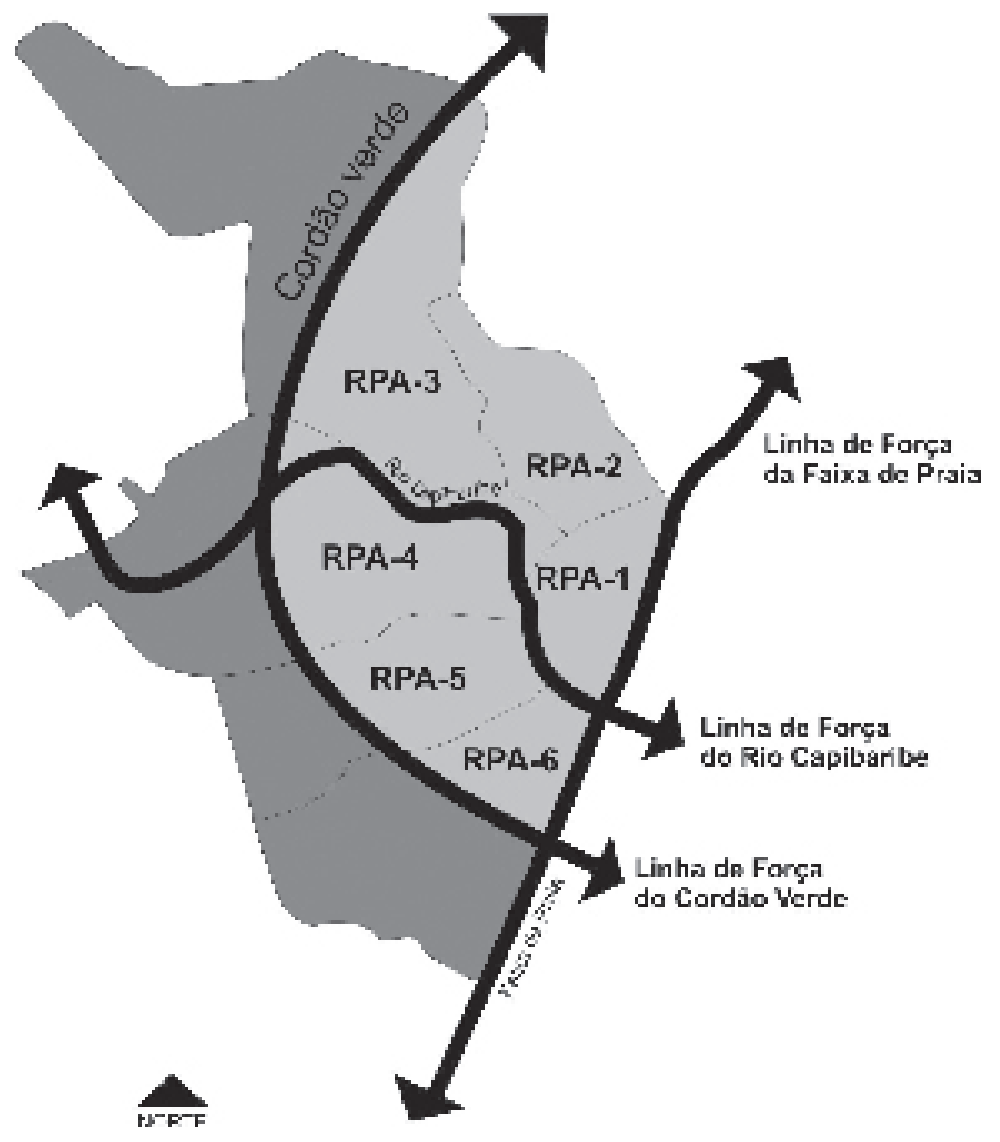

Mapa 2: Linhas de força da paisagem Fonte: Sá Carneiro e Mesquita (2000)

Nessa nova leitura, foram identificadas as linhas de força da paisagem, hoje evidentes, delineando e caracterizando o espaço; são elas: o rio Capibaribe, os morros que compõem as unidades de conservação e o litoral (CULLEN, 1980), (SÁ CARNEIRO e MESQUITA, 2000) e (BALTAR, 2000). O rio cortando a cidade de leste a oeste em um desenho sinuoso que parece ter sido referência para o traçado urbano apenas no início da ocupação; os morros formando um cordão verde de proteção do lado oeste, parecendo resultar de uma ação de compressão, de esmagamento que partiu do litoral, como se a condição urbana repelisse a proximidade com a vegetação densa $(\mathrm{HO}$ LANDA, 1976, p. 39), e o litoral, em linha reta e limitando uma ocupação compacta (Mapa 2).

Como mostra o Mapa 2, o cordão verde dos morros, formado pelas unidades de conservação, parte do conjunto dos espaços públicos de equilíbrio ambiental e cuja área corresponde a mais de $80 \%$ da área dos espaços livres da cidade, representa o parâmetro de maciço vegetal urbano para este estudo. São maciços vegetais os quais concentram elementos da paisagem natural - remanescente da mata atlântica-, amenizando a densidade construtiva dos bairros do entorno, mas que, de certo modo, expõem a fragmentação dos outros tipos de espaços livres da cidade (Foto 1). 
Foto 1: A Unidade de Conservação do

Parque dos Manguezais, com

212 ha, localiza-se entre a RPA6 e a área central - RPAT

Fonte: Acervo do Laboratório da Paisagem (2000)

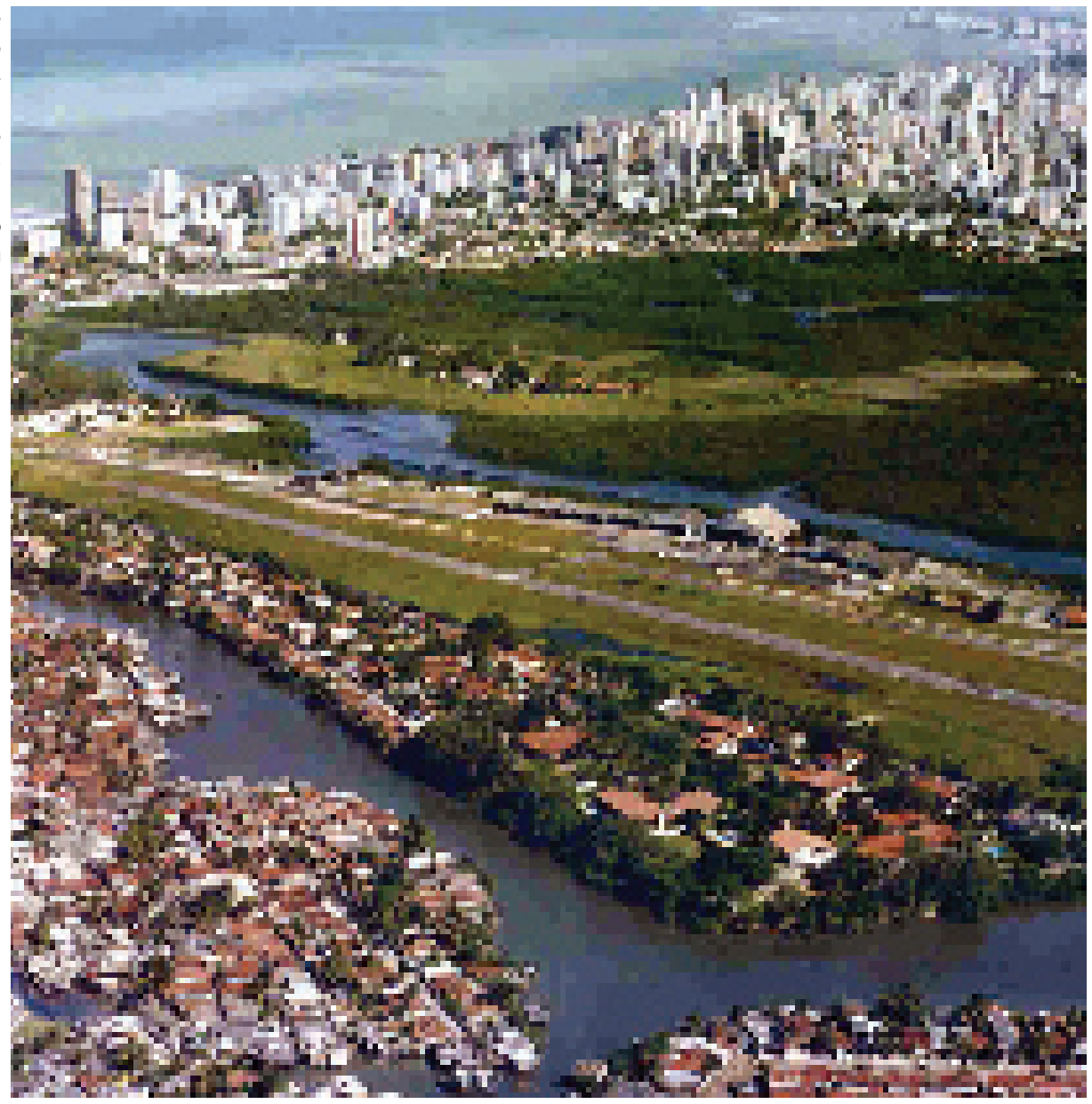

Assim, este trabalho apresenta as primeiras reflexões no sentido de avaliar a cobertura vegetal do Recife, caracterizando-a segundo as seis regiões políticoadministrativas - RPAs. De forma quantitativa, mediante a proporção dessa área verde considerada significativa em alguns tipos de espaços públicos, e, de forma qualitativa, observando sua distribuição na malha urbana, seu ritmo, proximidade dos maciços vegetais, enfim, relacionando dois princípios de concepção, característicos de sua formação ao longo da história: os princípios estéticos e os princípios ecológicos.

\section{Inspirando-se na História}

A paisagem recifense revela ações de iniciativas marcantes, em períodos importantes da história, mediante o tratamento estético dos espaços vegetados como uma expressão artística de compatibilidade ecológica com o caráter do sítio e destinados ao convívio da população. Os espaços verdes, portanto, exemplificaram cenários harmoniosos e contínuos, em uma relação de complementaridade com a arquitetura e o entorno, conforme pensa Sitte (1992). 
elemento vegetal participa da paisagem recifense sob diversas configurações: nas espécies de áreas remanescentes da mata atlântica, nos diversos tipos de mangue, no coqueiral da costa litorânea, nos sombreiros, acácias e castanholas predominantes nos parques e praças, além da mata ciliar das margens de rios (Foto 2). É possível dizer que o recifense tem uma relação histórica, social e paisagística com a vegetação, parecendo ter permanecido como uma relação muito mais de referência simbólica do que como uma relação de afetividade incorporada às suas práticas.

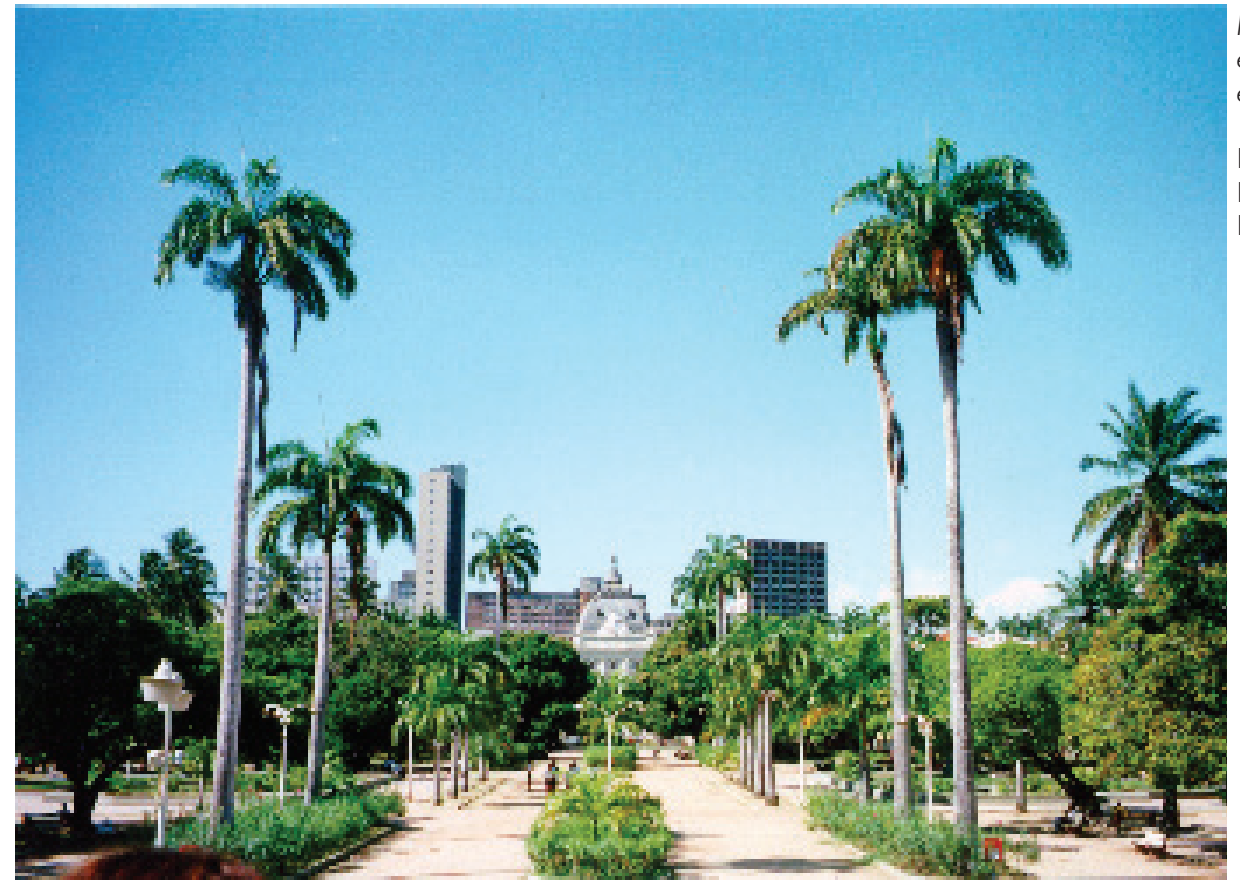

Foto 2: Vegetação estruturando o espaço do Parque 13 de Maio

Fonte: Acervo do Laboratório da Paisagem (2000)

Desde o século 17, no Parque de Friburgo criado por Maurício de Nassau, a vegetação exerceu preponderância, segundo uma estrutura verde de coqueiros enfileirados em sua função de referenciais do poder, cuja beleza paisagística foi reproduzida por Frans Post em cenários relacionados com as águas do rio (Foto 3). Ainda nesse período, a preocupação com o tratamento paisagístico contínuo impulsionou o plantio de coqueiros no denominado Terreiro dos Coqueiros onde fica, hoje, a Praça da Independência.
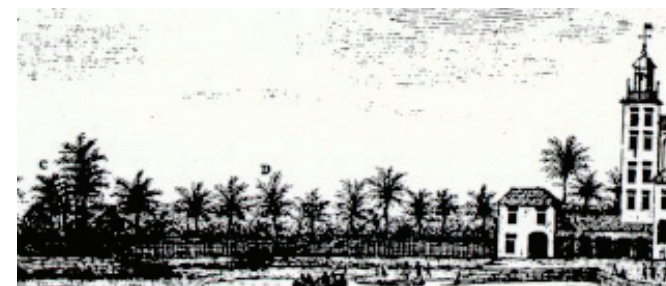

Foto 3: O Palácio de Friburgo e os coqueiros definem o parque na paisagem (séc. 17) Fonte: Atlas Histórico Cartográfico do Recife (1988) 
Propostas de espaços públicos articulados despontam no século 19, por exemplo, a que agrega o Parque 13 de Maio e a Praça da República, valorizando o rio Capibaribe na paisagem, preservando a vegetação e o projeto do parque, de influência renascentista (MENEZES, entrevista, 2000). Mas é na década de 30 que a presença do paisagista Burle Marx consolida a modelação de uma paisagem verde nos espaços públicos, combinando espelhos d’água com a flora regional e exótica, em uma composição plástica priorizando a estética e a ecologia. Caracterizam-se, nesse momento, intervenções pontuais nas quais ele cria, para cada jardim, um "motivo diferente", coincidindo com as intenções dos holandeses no trato dos espaços de convívio como verdadeiros jardins de contemplação. Por exemplo, pensou a Praça da República se prolongando até a margem do rio Capibaribe, em uma intenção de continuidade e integração (Diário de Pernambuco, 20 maio 1937), (Foto 4).
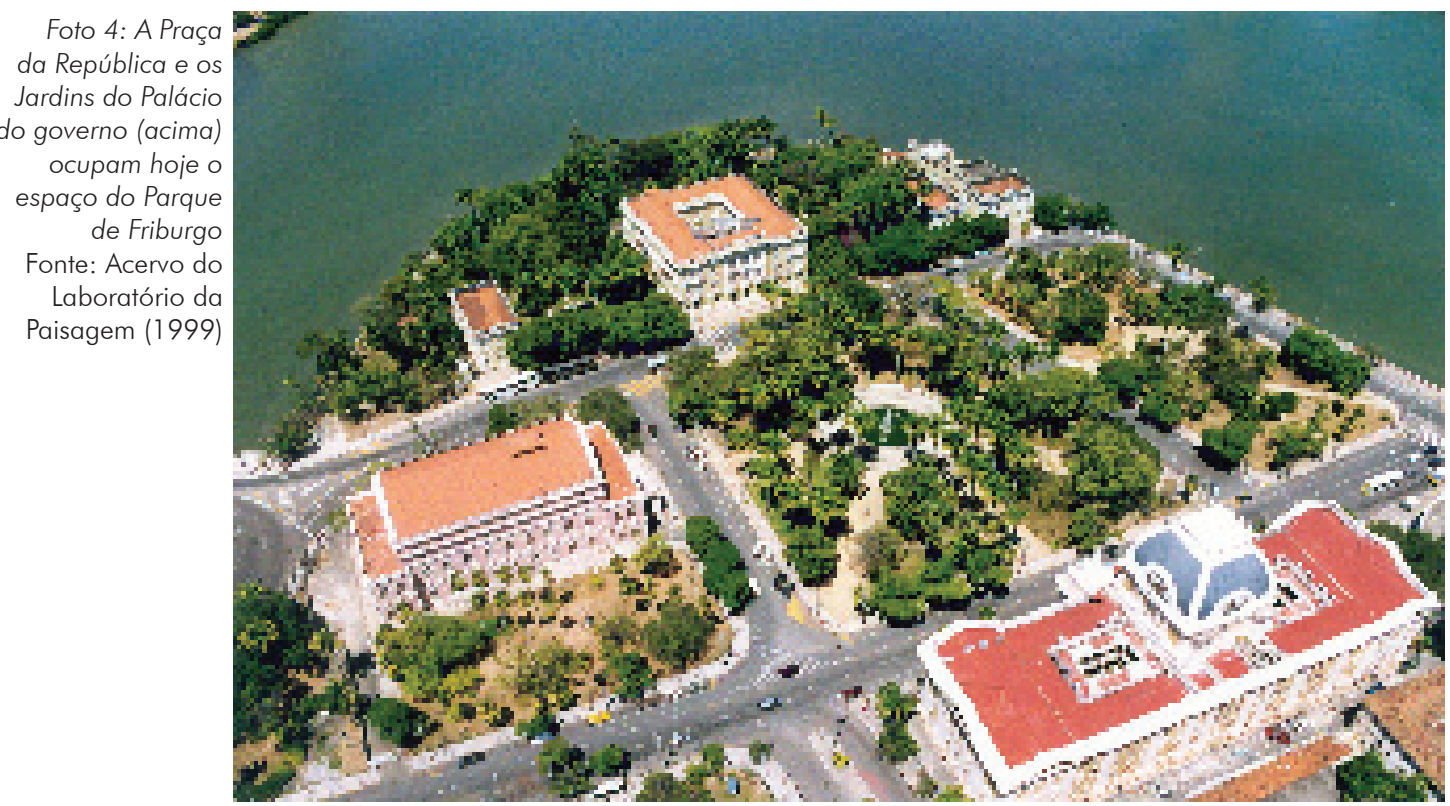

É nesse período que o higienismo influencia planos urbanísticos de remodelação, mediante propostas de espaços livres públicos integrados à estrutura urbana, então entendidos como espaços de renovação ambiental. Cinco planos foram propostos para o Recife, dos quais quatro valorizavam o rio Capibaribe, integrando-o às avenidas que se abriam criando parques, praças e jardins - o de Domingos Ferreira (1927), o de Fernando Almeida (1931), o de Nestor de Figueiredo (1932) e o de Ulhôa Cintra (1942) (BALTAR, 2000, p. 121). Nenhum desses planos foi concretizado, apenas intervenções pontuais aconteceram, posteriormente. Por outro lado, uma outra dinâmica de construção da cidade é percebida pelos arredores, sob a ordem da necessidade de sobrevivência, mediante aterros de mangues em uma busca de fixação no território. Assim também se vai estabelecendo uma outra relação, esta, de luta e competição com a natureza. 
Por volta da década de 50, os espaços públicos começam a perder sua expressividade e valor de comunicação e informação quando o Parque 13 de Maio, inaugurado em 1939, tem sua área inicial reduzida para a expansão do sistema viário e construção de edificações (RIBEIRO, 1998). A expansão urbana acelerada que se segue, com a implantação de loteamentos concebidos sob a ótica do lucro, desmembrando antigos sítios e chácaras das atuais zonas urbanas, comprometia cada vez mais o tecido urbano e a existência dos espaços livres (BALTAR, 2000, p. 84). Os espaços públicos passam a constituir espaços de sobras ou remanescentes do traçado desses loteamentos e da expansão do sistema viário. O rio, segundo Baltar (2000, p. 54), "o que há de mais típico na paisagem recifense", é abandonado na relação do projeto urbano e desprezado, tendo suas margens entulhadas de lixo (Foto 5). Nesse momento, com uma análise bastante detalhada, o professor Antonio Baltar apresenta seu estudo As diretrizes de um plano regional para o Recife (1951) para o provimento da cátedra de Urbanismo e Arquitetura Paisagística na Escola de Belas Artes da Universidade do Recife. Esse estudo agrega preocupações de expansão com a visão ecológica, econômica e estética, ao lado da ênfase dada à arquitetura paisagística que, no entanto, parece ter sido esquecida no planejamento da cidade.

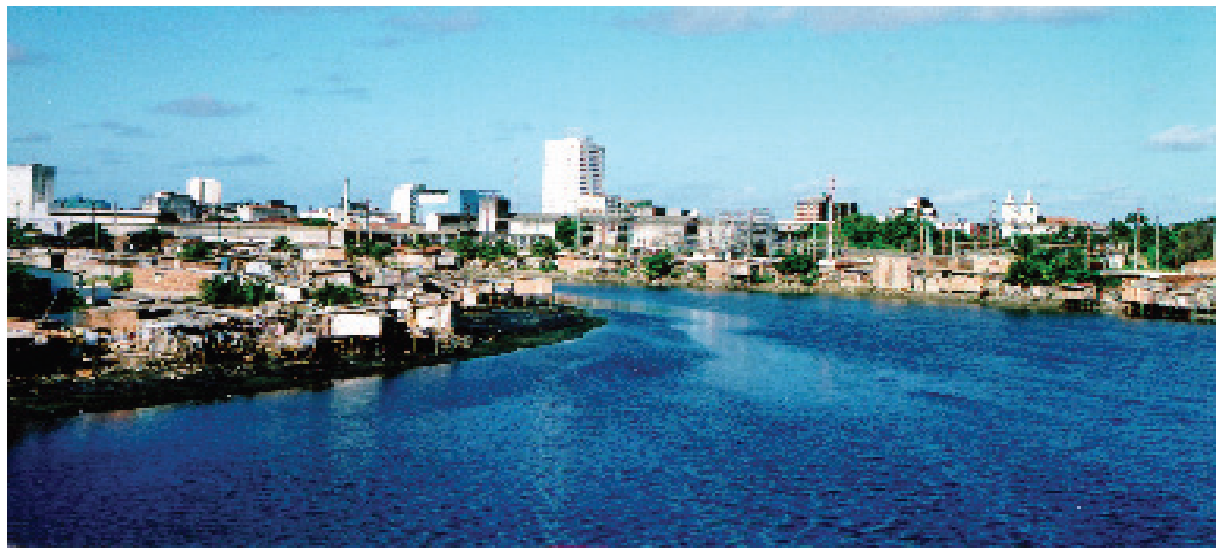

Foto 5:

A ocupação das favelas no centro do Recife congestionou o acesso às margens do rio Capibaribe Fonte: Acervo do Laboratório da Paisagem (2002)

Só nos anos de 1980 é que acontece a criação de dois parques como ações isoladas - o da Jaqueira e o de Santana -, embora originados de uma proposta mais ampla a qual incluía outros parques ao longo do rio Capibaribe (RIBEIRO, 1998). Expressa-se, de certo modo, uma preocupação com os espaços públicos, mas de forma localizada e direcionada para os bairros bem abastecidos, sem contemplar a cidade em sua totalidade. $O$ surgimento de outros parques e praças, daí em diante, procura atender muito mais às necessidades recreativas da população mediante a oferta de equipamentos esportivos, parecendo se desprender dos princípios estéticos e ecológicos das primeiras intervenções (Foto 6). Ao mesmo tempo, a construção de uma cidade vertical exige alargamento de vias e estacionamentos, em detrimento da perda dos jardins e quintais de antigas residências e da arborização de ruas. 


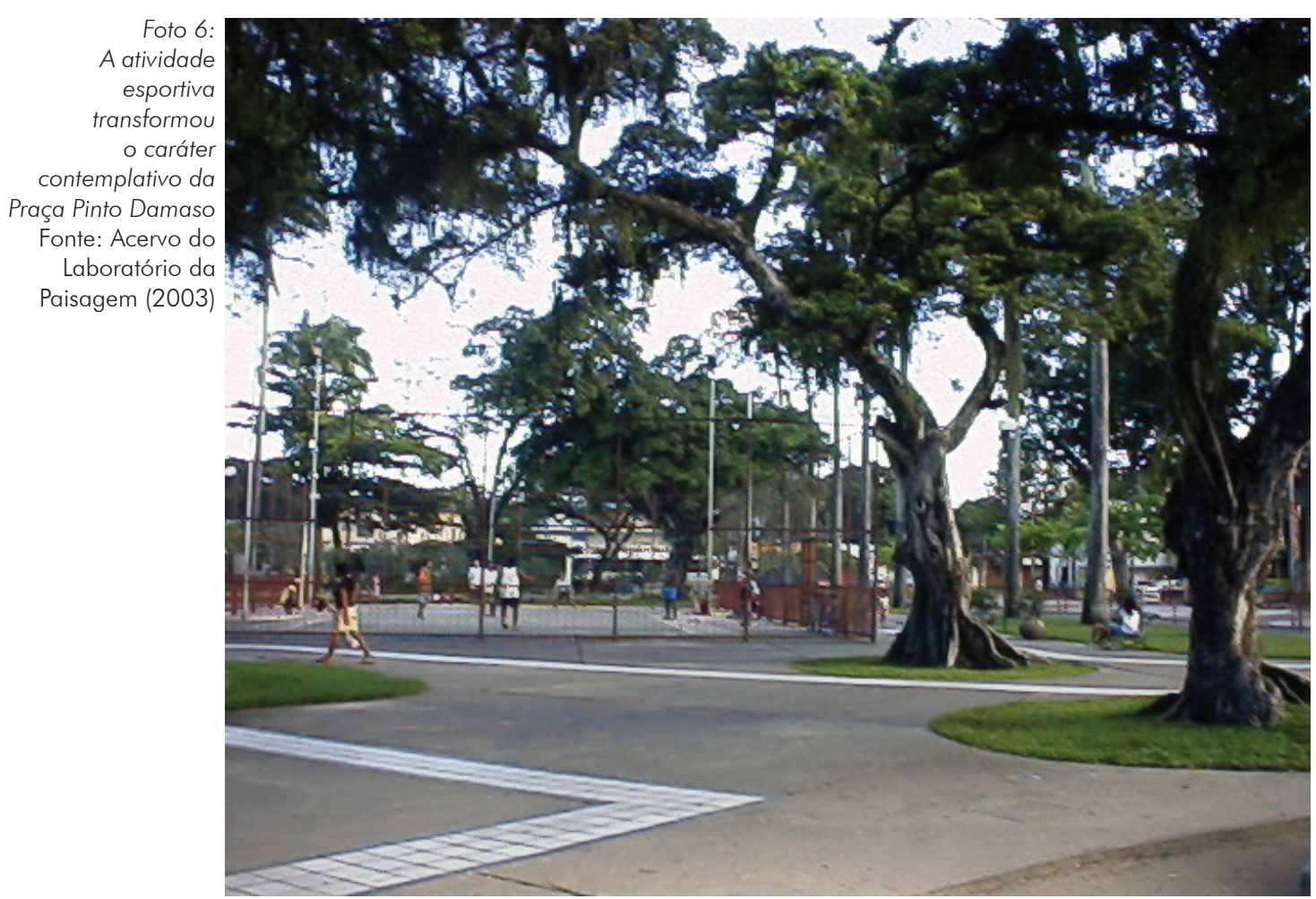

\section{Uma Avaliação do Verde nos Espaços Livres}

A caracterização da paisagem das regiões do Recife tem início com considerações sobre a vegetação, um elemento significativo na história de sua paisagem. Assim, buscou-se avaliar as condições da cobertura vegetal nos espaços livres, tomando por base o porcentual da vegetação nos parques, praças, jardins e unidades de conservação, visto que estes representam as concentrações significativas de áreas verdes como espaços bolsões de uso público nas funções de recreação e de equilíbrio ambiental. Dessa forma, excluem-se os jardins lineares então considerados como parte da arborização de ruas e os demais tipos de espaços públicos encontrados.

O porcentual da vegetação foi obtido na pesquisa Espaços Livres do Recife (2000) com a observação e avaliação in loco nos parques e nas praças, estimando-se uma proporção de área revestida de vegetação arbórea, arbustiva ou herbácea, de forma comparativa, com algumas praças referenciais analisadas pelo grupo. Além disso, foram levados em consideração aspectos qualitativos como a presença de praças mais representativas da cidade, que fizeram parte dos 43 espaços livres da amostra do livro Espaços livres do Recife (2000), a existência de praças projetadas pelo paisagista Burle Marx e, finalmente, a presença de vegetação densa nas unidades de conservação e da água no rio, mar ou lagoa. 
Sem dúvida alguma, as unidades de conservação com aproximadamente $100 \%$ de cobertura vegetal, a desenharem o cordão verde a oeste, acenam uma possibilidade de resgate dos espaços livres vegetados para equilibrar com os espaços edificados. Por sua concentração elas têm representatividade, correspondendo a $30 \%$ da área da cidade, o que não acontece com os outros tipos dos espaços verdes. Os parques, correspondendo a 0,20\%, e as praças, a 0,28\%, não expressam essa representatividade (SÁ CARNEIRO e MESQUITA, 2000, p. 43), (ver Tabela 1).

\begin{tabular}{|l|c|c|c|}
\hline \multicolumn{4}{|l|}{ Tabela 1: Proporção dos Espaços Verdes no Recife } \\
\hline Espaços Verdes & Quantidade & Área Total $\left(\mathrm{m}^{2}\right)$ & $\begin{array}{c}\text { \% em relação à área } \\
\text { da cidade }\left(^{*}\right)\end{array}$ \\
\hline UC's $^{\prime}$ & 19 & $66.041 .800,00$ & 30,00 \\
\hline Parques & 8 & $429.693,51$ & 0,20 \\
\hline Praças & 219 & $635.586,16$ & 0,28 \\
\hline Jardins & 21 & $72.636,00$ & 0,05 \\
\hline Total & 267 & $67.179 .715,00$ & 30,53 \\
\hline * Área da cidade $=220.000 .000,00 \mathrm{~m}^{2}$ \\
\hline
\end{tabular}

No propósito de relacionar a cobertura vegetal dos espaços verdes e das regiões do Recife com reflexo na paisagem, observa-se a projeção da RPA3, com 54,68\% de maciços vegetais, onde está situada a maior unidade de conservação Guabiraba/Pau-Ferro, com 3.674 ha; seguem-se a RPA4, com $28 \%$, e a RPA5, com 23\%, cujo uso predominante é o residencial. A RPA1, que consiste na área de ocupação mais antiga, mesmo com a presença do Parque 13 de Maio e da Praça da República, não possui expressiva proporção de área verde, mas, em compensação, desfruta de extensa superfície das águas do rio Capibaribe (ver Tabela 2).

\begin{tabular}{|l|r|r|r|r|}
\hline \multicolumn{3}{|c|}{$\begin{array}{c}\text { Tabela 2: Proporção de Cobertura Vegetal dos Espaços Verdes } \\
\text { por RPA }\end{array}$} \\
\hline RPA & $\begin{array}{c}\text { Área Total da } \\
\text { RPA }\left(\mathrm{m}^{2}\right)\end{array}$ & \multicolumn{3}{|c|}{ UC's, Parques, Praças e Jardins } \\
\cline { 3 - 5 } & & Área Total $\left(\mathrm{m}^{2}\right)$ & Área Cob. Veg. $\left(\mathrm{m}^{2}\right)$ & $\%$ Cobertura Vegetal \\
\hline 1 & $16.059 .000,00$ & $266.018,00$ & $192.510,70$ & 1,20 \\
\hline 2 & $14.300 .000,00$ & $579.735,00$ & $555.791,55$ & 3,89 \\
\hline 3 & $77.873 .000,00$ & $42.640 .475,00$ & $42.584 .414,05$ & 54,68 \\
\hline 4 & $42.141 .000,00$ & $11.907 .057,00$ & $11.806 .834,30$ & 28,02 \\
\hline 5 & $30.103 .000,00$ & $7.231 .470,00$ & $7.175 .863,10$ & 23,84 \\
\hline 6 & $39.018 .000,00$ & $4.742 .435,00$ & $4.656 .387,20$ & 11,93 \\
\hline
\end{tabular}

A influência exercida pela presença da cobertura vegetal nessas regiões está refletida na condição privilegiada do maior convívio com o verde encontrado em determinados bairros os quais contêm unidades de conservação e parques 
em seu domínio, como o bairro da Jaqueira com 25\% de área verde, o de Dois Irmãos, com 75\%, e o de Guabiraba, com 87\% na RPA3; a Várzea, com 49\%, na RPA4; o Barro, com 49\%; Jiquiá, com 33\%; Curado, com 49\% na RPA5; e o Pina, com 35\% na RPA6. Na verdade, essa avaliação por bairro justifica-se para evidenciar que 40\% dos 94 bairros da cidade têm menos de $1 \%$ de cobertura vegetal, mesmo se reconhecendo que a função de equilíbrio ambiental desses espaços extrapola os limites do bairro (ver Tabela 3).

\begin{tabular}{|c|c|c|c|c|c|c|}
\hline \multicolumn{7}{|c|}{$\begin{array}{c}\text { Tabela 3: Presença dos Espaços Verdes - UC's e Parques - } \\
\text { nos Bairros por RPA }\end{array}$} \\
\hline \multirow{2}{*}{$\begin{array}{l}\text { Espaços } \\
\text { Verdes }\end{array}$} & \multicolumn{6}{|c|}{$\%$ da cobertura vegetal nos bairros por RPA } \\
\hline & 1 & 2 & 3 & 4 & 5 & 6 \\
\hline \multirow[t]{3}{*}{ UC } & & & Dois Irmãos (75\%) & Várzea (49\%) & Barro $(49 \%)$ & Pina (41\%) \\
\hline & & & \multirow[t]{2}{*}{ Guabiraba (87\%) } & & Jiquiá (33\%) & \\
\hline & & & & & Curado (49\%) & \\
\hline Parque & & & Jaqueira (25\%) & & & \\
\hline
\end{tabular}

\section{Tabela 4: Quantidade dos Espaços Verdes - UC's, Parques, Praças e Jardins}

\begin{tabular}{|l|r|r|r|r|r|r|r|}
\hline Espaços Verdes & RPA 1 & RPA 2 & RPA 3 & RPA 4 & RPA 5 & RPA 6 & Total \\
\hline Unidades de Conservação & 1 & 1 & 3 & 4 & 6 & 4 & 19 \\
\hline Parque & 1 & 0 & 3 & 3 & 0 & 1 & 8 \\
\hline Praça & 32 & 21 & 33 & 33 & 39 & 61 & 219 \\
\hline Jardim & 6 & 2 & 5 & 3 & 1 & 4 & 21 \\
\hline Total & 40 & 24 & 44 & 43 & 46 & 70 & 267 \\
\hline
\end{tabular}

Por sua vez, a quantidade desses espaços verdes informa que o Recife tem uma tradição de praças por seu maior número (219), seguido dos jardins (21), mas acusando sua carência de grandes espaços livres de recreação, como os parques, que são apenas oito. Destes, três estão na RPA3, com estado de conservação regular e bom, e três estão na RPA4, dos quais um se encontra em estado de abandono. A maioria dos espaços verdes está concentrada na RPA6 (70) pelo número maior de praças (61), o que pode estar relacionado à expansão dos bairros populares para o lado sul em meados do século passado, seguida das RPAs 5, 3 e 4, cuja quantidade se equivale.

É nas praças projetadas pelo paisagista Burle Marx que a vegetação aparece, de maneira expressiva, como o principal componente da paisagem, concentrando-se na RPA3: as praças de Casa Forte, do Derby, do Entroncamento e Faria Neves. Na RPA1 estão situadas as praças da República e Artur Oscar e, na RPA4, as praças Euclides da Cunha e Pinto Damaso. E, finalmente, na RPA6, a Praça Ministro Salgado Filho, (Foto 7). 


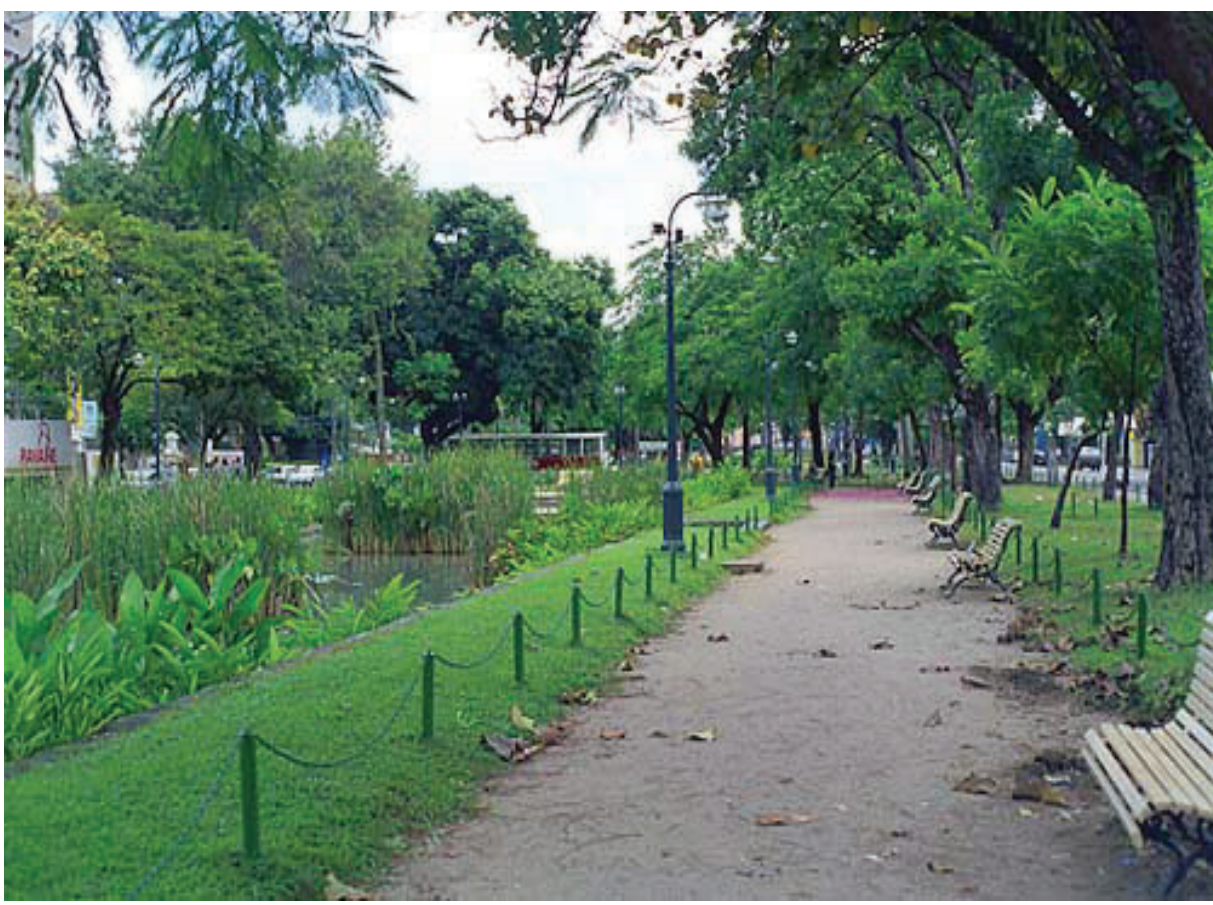

Foto 7: A Praça de Casa Forte tem uma paisagem valorizada pelas diferentres espécies vegetais e a presença de água Fonte: Acervo do Laboratório da Paisagem (2002)

No que se refere à proporção da cobertura vegetal do conjunto dos espaços verdes selecionados (267), 89 espaços estão inseridos no intervalo de 76 a $100 \%$ de cobertura vegetal e 56 deles estão no intervalo de 51 a $75 \%$ (ver Tabela 5). Segundo os dados da pesquisa Espaços Livres do Recife (2000), a cobertura vegetal aparece como característica marcante das praças do Recife, quando analisados isoladamente, uma vez que 99 das 219 praças possuem mais de $50 \%$ de sua área com vegetação.

\begin{tabular}{|l|c|c|c|c|c|}
\hline \multicolumn{7}{|l|}{ Tabela 5: Quantidade de Espaços Verdes por Intervalo de } \\
Proporção de Cobertura Vegetal por RPA \\
\hline RPA & 0 a 25\% & 26 a $50 \%$ & 51 a $75 \%$ & 76 a $100 \%$ & Total \\
\hline 1 & 7 & 14 & 4 & 14 & 39 \\
\hline 2 & 5 & 8 & 2 & 9 & 24 \\
\hline 3 & 4 & 3 & 12 & 24 & 43 \\
\hline 4 & 2 & 9 & 13 & 19 & 43 \\
\hline 5 & 10 & 15 & 8 & 13 & 46 \\
\hline 6 & 17 & 6 & 17 & 10 & 50 \\
\hline Total & 45 & 55 & 56 & 89 & 245 \\
\hline
\end{tabular}

Segundo a avaliação exposta, a partir dos dados ecológicos, estéticos e recreativos, deduz-se que a RPA3 é a região mais bem servida, não só no aspecto de amenização ambiental, mas também na qualidade estética da paisagem e na oferta de equipamentos recreativos pela presença dos parques. Essa região agrega não só a maior área das unidades de conservação 
- Guabiraba e Dois Irmãos - como também a maior presença das praças projetadas pelo paisagista Burle Marx.

\section{Projetando o Verde no Recife}

Retomando nosso ponto de partida, as linhas de força da paisagem, e na preocupação com a leitura da paisagem como sistema integrado pela vegetação, pergunta-se: Até que ponto esses espaços contínuos podem sugerir alguma articulação com os outros tipos de espaços livres?

A leitura do espaço urbano no mapa georreferenciado dos espaços livres do Recife (SÁ CARNEIRO e MESQUITA, 2000) revela que o conjunto de espaços livres salientado, em parte, articulado, é o das unidades de conservação por seu desenho natural contínuo. E essa leitura aponta para as três linhas de força da paisagem como indicadores de uma perspectiva que poderá projetar o verde, articulando os espaços livres. E como isso acontecerá?

Em uma visão sintética, as linhas de força - o rio, os morros e o litoral - são os suportes, os contínuos, os geradores de uma nova forma e escala, os quais podem reunir espaços maiores e menores, desde que guardem relações de escala, estética e unidade. São os fios condutores da paisagem da cidade, os modeladores da forma da cidade, além de proporcionarem pontos de mirante (DE PAOLI, 2001). Por sua vez, os pequenos espaços livres inseridos na malha urbana densa e tradicional são fundamentais em sua leitura, qualquer que seja a escala considerada. Porém, a densidade construtiva, além de restringir a imagem panorâmica e a escala dos conjuntos urbanos, tem contribuído para a saturação dos espaços livres e das infra-estruturas (PLANO VERDE DE LISBOA, 1997).

Assim, a estrutura dos espaços livres do Recife poderá ter dois níveis de apreensão. $\bigcirc$ primeiro é o da estrutura envolvente, que abrange os espaços contínuos - o rio, as unidades de conservação e o litoral - e o segundo é o da estrutura interior, à qual está entremeada, espalhada entre os espaços edificados, concedendo coerência ao tecido urbano, e que precisa ser ativada ou articulada com a primeira. A estrutura envolvente e a estrutura interior guardam, então, uma relação não só de escala, mas também de hierarquia com relação ao tamanho (PLANO VERDE DE LISBOA, 1997). Por exemplo, é possível se estabelecer corredores interligando as unidades de conservação com os parques urbanos - públicos e de vizinhança - e algumas praças ou outros tipos de espaços livres. É o que pressupõe os objetivos do Plano Verde de Lisboa ao relacionar os espaços livres de forma contínua, complementar e estrutural - de origem histórica, social ou cultural -, muito mais do que estabelecer parâmetros ou cotas ideais de área verde, que, muitas vezes, não agregam as especificidades dos devidos locais. 
A perspectiva de conservação dos espaços vegetados no planejamento da cidade reside, portanto, na adoção dos princípios estéticos e ecológicos anteriormente condutores dos projetos urbanos e que hoje permanecem presentes nas Cartas Patrimoniais da Unesco, como a Carta de Florença de 1981, referente aos jardins históricos. Esses princípios podem ser vistos como valores históricos fundamentais para a conservação do patrimônio ambiental e cultural que é a paisagem cultural, conferindo a identidade do lugar aos seus construtores. Isso poderia ser perseguido tomando-se como parâmetro o desenho integrado das unidades de conservação, que poderá se articular com os outros tipos de espaços livres, segundo corredores verdes potenciais, como, por exemplo, os 66 canais distribuídos na malha urbana, com os rios e o mar.

desenho do conjunto das unidades de conservação sugere que esses maciços vegetais sejam disseminados de forma tentacular, do oeste para o leste, no sentido inverso da ocupação da cidade, penetrando no entremeado da malha e projetando da paisagem natural uma outra paisagem, a paisagem cultural, segundo princípios estéticos e ecológicos que refletirão uma nova linguagem da paisagem (SPIRN, 1998) (Mapa 2). Evidentemente que a leitura das formas da paisagem pressupõe o envolvimento dos atores sociais em diversas instâncias, em um processo de gestão integrada que garanta essa conservação almejada.

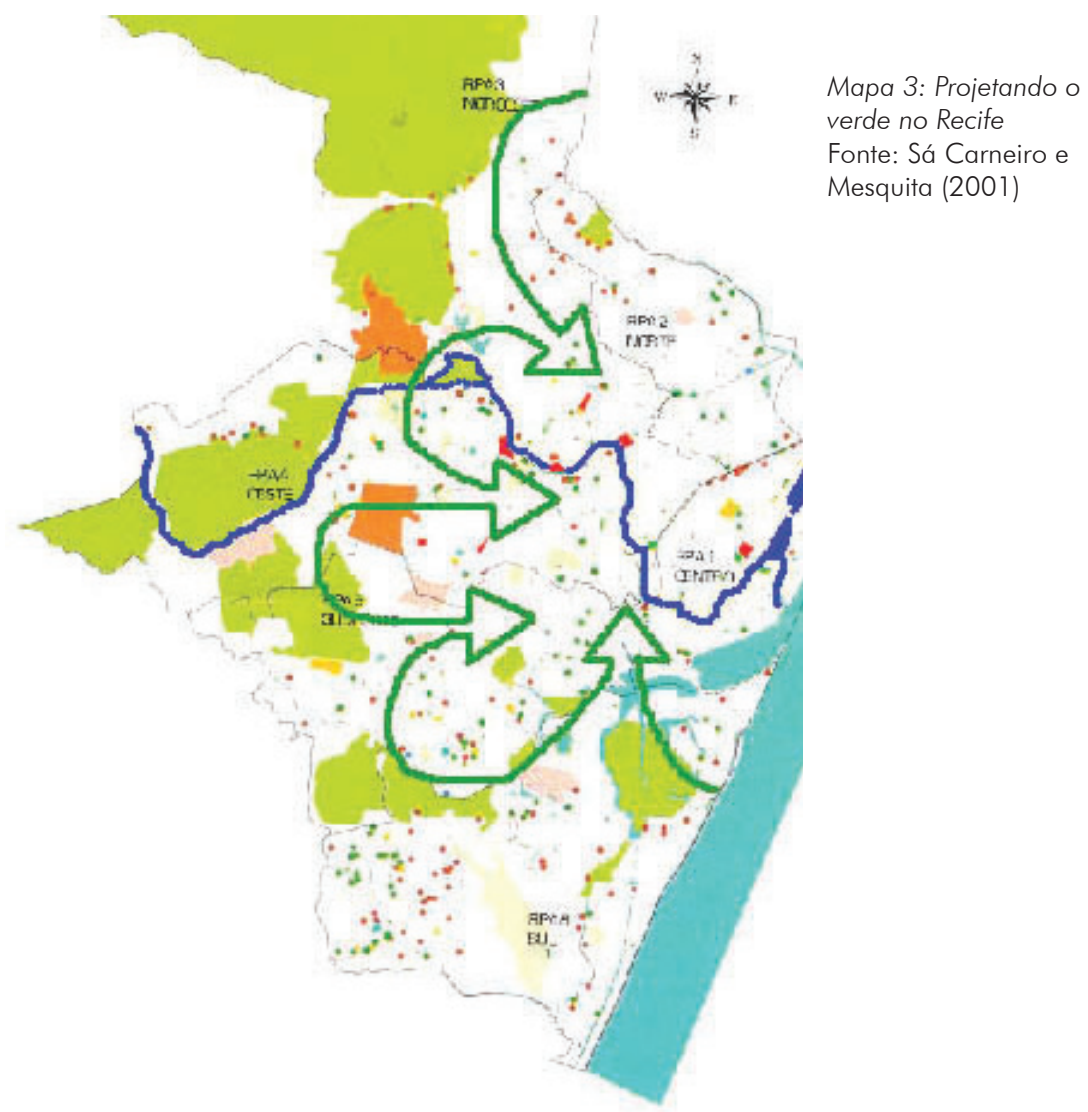




\section{Bibliografia}

A REFORMA dos jardins do Recife. Diario de Pernambuco, Recife, 20 maio 1937.

CULLEN, Gordon. Paisagem urbana. Lisboa: Edições 70, 1971.

DE PAOLI, Paula. A estrutura latente. Jornal da Paisagem, [S.I.: s. n.], 1997. [Citado em 8 maio 1997]. http://www.jornaldapaisagem.com.br

HOLANDA, Armando de. Roteiro para construir no Nordeste. Recife: UFPE, 1976.

MENEZES, José Luiz Mota (Org.). Atlas histórico cartográfico do Recife. Recife: Fundaj/Massangana, 1988.

PLANO VERDE DE LISBOA. Componente do Plano Director Municipal de Lisboa. Organizado por Gonçalo Ribeiro Telles. Lisboa: Colibri, 1997.

RIBEIRO, Ana Rita Sá Carneiro. O projeto paisagístico, as funções e o uso dos parques urbanos - o Parque 13 de Maio. Revista Clio do Programa de Pós-graduação em História - UFPE, Recife, n. 18, p. 17-25, 1998.

SÁ CARNEIRO, Ana Rita; MESQUITA, Liana. Espaços livres do Recife. Recife: Prefeitura do Recife/UFPE, 2000.

SITTE, Camillo. A construção das cidades segundo seus princípios artísticos. São Paulo: Ática, 1992.

SPIRN, Anne Whiston. The language of landscape. New Haven/Londres: Yale University Press, 1998. 